\title{
Indicadores de Desenvolvimento Sustentável: uma análise no território do Cariri
}

\section{Oriental Paraibano}

\author{
Sustainable Development Indicators: an analysis in the territory of the Eastern Cariri Paraibano \\ Indicadores de Desarrollo Sostenible: un análisis en el territorio del Cariri Paraibano Oriental
}

Recebido: 17/01/2022 | Revisado: 21/01/2022 | Aceito: 27/01/2022 | Publicado: 29/01/2022

\author{
José Erivaldo da Silva ${ }^{1}$ \\ ORCID: https://orcid.org/0000-0001-6682-852X \\ Universidade Federal de Campina Grande, Brasil \\ E-mail: jerysilva85@gmail.com \\ Maria de Fátima Martins ${ }^{2}$ \\ ORCID: https://orcid.org/0000-0002-9578-9555 \\ Universidade Federal de Campina Grande, Brasil \\ E-mail: fatimamartins2005@gmail.com
}

\begin{abstract}
Resumo
Promover um sistema integrado para mensurar o desempenho econômico, social e ambiental é fundamental para auxiliar a gestão de estabelecimentos rurais, sendo capaz de apontar as potencialidades endógenas para alcançar o desenvolvimento sustentável. Esse trabalho tem como objetivo principal analisar o desenvolvimento regional sustentável no Território do Cariri Oriental Paraibano.Tem-se como base teórica os trabalhos de Agenda 21, Ferreira et. al. (2012), May (2010), Baroni (2001), Wanderley (2001), Mol (2000), entre outros. Os dados foram coletados nos relatórios das secretarias municipais de agricultura e desenvolvimento, no relatório do PTDRS - Plano Territorial de Desenvolvimento Rural Sustentável do Cariri Oriental, nos documentos da Secretaria de Desenvolvimento Territorial - SDT vinculada ao Ministério do Desenvolvimento Agrário - MDA e do IBGE. A justificativa básica é que nos últimos anos o território tem sido beneficiado com políticas de desenvolvimento sustentável, voltada para a produção familiar, a exemplo da Lei 11.947/2009 e de movimentos ligados a produção agroecológica sustentável. A hipótese de que a agricultura familiar no território assemelha-se a agricultura patronal é validada à medida que o planejamento da produção tem por base o mercado e não o consumo familiar ao mesmo tempo em que a mão de obra, a propriedade e o usufruto da terra tem em sua essência a família, verifica-se a atividade como resultado do esforço familiar e promovedora de sustentabilidade econômica, equidade ambiental e responsabilidade social. Os dados demonstram que os municípios margeados por BRs e/ou possuem atividades não essencialmente rurais, têm o maior IDH, evidenciando que apesar da maior parte da mão de obra ocupada no território está vinculada a agricultura familiar, essa não é capaz de gerar sustentabilidade econômica, apesar de ser a melhor aposta para a sustentabilidade ambiental.
\end{abstract}

Palavra-chave: Agricultura familiar; Desenvolvimento; Sustentabilidade e ambiente.

\begin{abstract}
Promoting an integrated system to measure economic, social and environmental performance is fundamental to assist the management of rural establishments, being able to point out the endogenous potential to achieve sustainable development. This work has as main objective to analyze the sustainable regional development in the Territory of Cariri Oriental Paraibano.The theoretical basis is the work of Agenda 21, Ferreira et. Al. (2012), May (2010), Baroni (2001), Wanderley (2001), Mol (2000), among others. Data were collected in the reports of the municipal departments of agriculture and development, in the report of ptdrs - Territorial Plan for Sustainable Rural Development of The Eastern Cariri, in the documents of the Secretariat of Territorial Development - SDT linked to the Ministry of Agrarian Development - MDA and IBGE. The basic justification is that in recent years the territory has benefited from sustainable development policies, focused on family production, such as Law 11.947/2009 and movements related to sustainable agroecological production. The hypothesis that family farming in the territory resembles employer's agriculture is validated as production planning is based on the market and not family consumption at the same time that the labor, property and enjoyment of the land has in its essence the family, the activity is verified as a
\end{abstract}

\footnotetext{
${ }^{1}$ Doutorando em Gestão de Recursos Naturais - UFCG, Mestre em Desenvolvimento Regional - UEPB, Especialista em Desenvolvimento Sustentável UFCG; Bacharel em Economia - UFCG, Cientista Agrário - UFPB.

${ }^{2}$ Doutora em Recursos Naturais pela UFCG. Mestre em Engenharia de Produção pela Universidade Federal da Paraíba e Especialista em Marketing pela Universidade Estadual da Paraíba. Possui graduação em Administração de Empresas e Administração Pública pela Universidade Federal da Paraíba e graduação em Comunicação Social (Jornalismo) pela Universidade Estadual da Paraíba. Professora do Curso de Administração da Universidade Federal de Campina Grande (UFCG), do Programa de Pós Graduação em Administração (PPGA/UFCG) e professora e Coordenadora do Programa de Pós Graduação em Recursos Naturais (PPGRN/UFCG). Líder do Grupo de Pesquisa GEPIS - Grupo de Estudos e pesquisa em Indicadores de Sustentabilidade e Coordenadora do Projeto Centro de Desenvolvimento Regional - CDR Paraíba.
} 
result of the family effort and promoting economic sustainability, environmental equity and social responsibility. The data show that the municipalities bordered by BRs and/or have non-essentially rural activities, have the highest HDI, showing that despite the majority of the labor occupied in the territory is linked to family agriculture, this is not able to generate economic sustainability, despite being the best bet for environmental sustainability.

Keywords: Family agriculture; Development; Sustainability and the environment.

\section{Resumen}

Los datos muestran que los municipios delimitados por BR y/o que tienen actividades no esencialmente rurales, tienen el IDH más alto, mostrando que a pesar de que la mayoría de la mano de obra ocupada en el territorio está vinculada a la agricultura familiar, esta no es capaz de generar sostenibilidad económica, a pesar de ser la mejor apuesta para la sostenibilidad ambiental. vinculado al Ministerio de Desarrollo Agrario - MDA e IBGE. La justificación básica es que en los últimos años el territorio se ha beneficiado de políticas de desarrollo sostenible, centradas en la producción familiar, como la Ley 11.947/2009 y movimientos relacionados con la producción agroecológica sostenible. La hipótesis de que la agricultura familiar en el territorio se asemeja a la agricultura patronal se valida ya que la planificación productiva se basa en el mercado y no en el consumo familiar al mismo tiempo que el trabajo, la propiedad y el goce de la tierra tiene en su esencia la familia, la actividad se verifica como resultado del esfuerzo familiar y promoviendo la sostenibilidad económica, equidad ambiental y responsabilidad social. Los datos muestran que los municipios delimitados por BR y/o que tienen actividades no esencialmente rurales, tienen el IDH más alto, mostrando que a pesar de que la mayoría de la mano de obra ocupada en el territorio está vinculada a la agricultura familiar, esta no es capaz de generar sostenibilidad económica, a pesar de ser la mejor apuesta para la sostenibilidad ambiental.

Palabras clave: Agricultura familiar; Desarrollo; Sostenibilidad y medio ambiente.

\section{Introdução}

O dinamismo econômico não se irradia homogeneamente para todas as regiões de um país e tampouco permitem uma distribuição equitativa da renda entre os diversos grupos sociais. As desigualdades regionais têm sido constantemente questões de debate nas universidades, nos centros tecnológicos e instituições governamentais e não governamentais, especialmente a partir da década de 1980 do Século passado.

O desenvolvimento econômico dinâmico é resultado das políticas desenvolvidas a partir do pensamento integrativo do próprio processo de desenvolvimento regional, de sorte que aspectos como equidade ambiental, responsabilidade social e viabilidade econômica toma vultos significativos no processo de desenvolvimento das políticas para dinamizar a economia regional Silva (2016).

Nesse contexto, as políticas dos governos locais deveriam buscar a valoração das políticas públicas para potencializar a economia regional sem comprometer o futuro dos recursos naturais, sociais e culturais, em contra ponto com as tendências globalizantes de internacionalização do capital intensificado pelo processo de reconfiguração dos padrões de produção, assim como pela internacionalização dos fluxos de capital, expressando alto grau de desenvolvimento tecnológico e elevando o desemprego estrutural.

Elementos do crescimento econômico como descrito acima, são fatores determinantes para a (re)organização do processo produtivo, a partir do desenvolvimento das potencialidades locais, com mudanças significativas nos paradigmas produtivos, especialmente a partir da publicação do Relatório Brundtland - Our Common Future publicado em 1987, que responsabiliza as ações da humanidade de forma globalizada, trazendo nesse sentido, a discussão dos problemas ambientais para todas as esferas do pensamento do desenvolvimento, Tsur (2021).

Os movimentos voltados ao desenvolvimento local deveriam tomar por base as diretrizes do Relatório Brundtland, assim como à Agenda 21, discutindo o desenvolvimento como integrado e sustentável, que grosso modo, respaldam para o desenvolvimento endógeno, capaz de compreender as desigualdades regionais e promover instrumentos de políticas para a correção dessas desigualdades, o desenvolvimento endógeno busca o fortalecimento e qualificação das estruturas internas de um território Amaral Filho (1996); Chen et. al (2020), na tentativa da consolidação do desenvolvimento local, criando 
condições sociais e econômicas para a geração e atração de novas atividades produtivas, inclinando-as para as potencialidades ambientais e culturais do território ao máximo de suas potencialidades.

Nesse sentido, torna-se necessário compreender a endogenia como complementar a critérios de sustentabilidade, diferenciando-a do conceito originário da década de 1970, quando se destaca as propostas de desenvolvimento da base para o topo, considerando só e somente só aspectos como capital financeiro, disponibilidade de mão de obra e tecnologia, desconsiderando as relações desses com as questões ambientais, sociais e culturais. Tsur (2021).

A principal contribuição da teoria endogensita para o modelo atual de desenvolvimento, no qual as condições de sustentabilidade são sempre postas em evidências é verificar como as instituições e os fatores de produção, decisivos para desenvolvimento, tais como, capital social, capital humano, conhecimento, pesquisa e desenvolvimento e a informação Cavalcanti et. al. (2021), podem ser gerenciados dentro do território e não mais de forma exógena, e possibilitando promover sustentabilidade no desenvolvimento, considerando as relações do desenvolvimento com equidade ambiental, responsabilidade social e viabilidade econômica, percebendo que a região e/ou o território dotado desses fatores ou estrategicamente direcionado para desenvolvê-los internamente tem maior potencial de dinamizar a economia e promover o desenvolvimento local integrado e sustentável, Mendes Junior (2020).

Desse modo e entendendo o desenvolvimento local integrado e sustentável como um mecanismo capaz de compreender as identidades locais, o estudo aqui proposto tem como objetivo avaliar o desenvolvimento regional sustentável no Território do Cariri Oriental Paraibano. A hipótese básica é que a agricultura familiar no território apresenta características essencialmente mercadológicas, diferenciando da agricultura patronal apenas pelas condições de mão de obre, pose da terra e tecnologia aplicada, mas o viés produtivo e o planejamento dessa produção objetiva a comercialização do produto final mesmo que in natura. A hipótese secundaria é que mesmo com característica produtiva voltada para o mercado, o produto local referencia-se por sua identidade cultural, resguardando característica ímpares condicionando o território ao desenvolvimento local integrado e sustentável, desde que as políticas locais e os agentes locais fortaleçam em suas decisões essas características.

$\mathrm{O}$ presente estudo justifica-se pelos constantes ganhos de escala na produção local com identidade produtiva e mercadologia própria, assim como o respeito ao meio ambiente, responsabilidade social e viabilidade econômica. Como característica de identidade na produção familiar pode ser citado a produção de caprinos nos municípios de Cabaceiras, Gurjão e Barra de São Miguel, a produção de mel em Barra de São Miguel e Caturité assim como, a produção familiar dos mais diversos aspectos produtivos nos 14 (quatorze) municípios que compõem o território e que foram objeto de análise nesse estudo.

Como instrumento de análise tomou-se os relatórios das secretarias municipais de desenvolvimento econômico dos municípios, o PTDRS (2010) - Plano Territorial de Desenvolvimento Rural Sustentável e os documentos oficiais do MDA Ministério do Desenvolvimento Agrário, e dados do IBGE - Instituto Brasileiro de Geografia e Estatística.

Como indicadores de desenvolvimento foi utilizado às relações ente o PIB local, o PIB Per Capital e o IDH, considerando as condições de crescimento desses índices e a relação com a qualidade de vida das famílias agricultoras, assim como as condições sócias culturais dos municípios que compõem o território, as discussões dos dados observados foram medidos a luz dos relatórios da Secretaria de Desenvolvimento Territorial do Ministério do Desenvolvimento Agrário (2010), aos conceitos de agricultura familiar, tomou-se por base Wanderley (2001), assim como para indicadores de sustentabilidade e o próprio entendimento do desenvolvimento sustentável Ferreira (2012), Gonçalves (s/d), Carvalho (2010) entre outros.

Os indicadores de desenvolvimento sustentável demonstram o quão uma região ou localidade caminha no sentido da promoção do desenvolvimento com equidade entre o meio ambiente, as produção de bens, serviços e mercadorias e a distribuição desses entre as pessoas, oportunizando aos formuladores de políticas condições de resolução de problemas que estejam diretamente ligados ao processo de produção, para o Cariri Oriental Paraíbano, os indicadores tem possibilitado aos 
tomadores de decisão mecanismos que grosso modo tem promovido o desenvolvimento com sustentabilidade, como poderá ser melhor visualizados nos resultados e discussões.

\section{Fundamentação Teórica}

\subsection{Agricultura Familiar}

A agricultura familiar é uma atividade econômica, e, portanto, uma categoria analítica, como lócus nas ações do governo em busca do desenvolvimento rural, estabelecendo critérios que delimitem esse conjunto social às condições de desenvolvimento social e econômico com responsabilidades ambientais Leopoldo et. al, (2020), de modo que a agricultura familiar não permite analises apenas como um instrumento político, oriundo nas discussões sindicais, religiosos e políticos atrelados a módulos rurais, detentora de condições sui generis de subsistência.

De acordo com a Lei 11.326/2006, “(...) considera-se agricultor familiar e empreendedor familiar rural aquele que praticar atividade no meio rural, atendendo simultaneamente, aos seguintes requisitos: (I) não detenha, a qualquer título, área maior do que quatro módulos rurais; (II) utilize predominantemente mão de obra da própria família (...); (III) tenha renda familiar predominantemente originada de atividades econômicas vinculadas ao próprio estabelecimento ou empreendimento". Os critérios descritos acima para agricultura familiar não vinculam à atividade a critérios econômicos, o que dificulta o desenho das políticas para o setor.

A razão da dificuldade citado acima pela Lei, 11.326/2006, justifica-se por critérios de uma teoria de exploração social que é parte de algumas tradições teóricas das ciências sociais, normalmente perspectiva anticapitalista, vinculando à agricultura familiar, as beneficies dos critérios sociais religiosos, afastando-a dos critérios capitalistas, na defesa de que o mundo rural deve ser ocupado apenas por propriedades familiares, nas quais os membros da família sejam também, os próprios trabalhadores, não existindo assim a exploração do trabalho assalariado.

O senso comum parece aceitar que sempre teria sido a agricultura familiar um conjunto social sem nenhum desafio de definição, sugerindo nas entre linhas uma referência aos pequenos produtores e apontando para as famílias rurais com menores recursos, inclusive no tocante ao acesso à terra. No entanto, a agricultura familiar é uma atividade de importância economia considerável, no Brasil representando Mais de $84 \%$ do total dos estabelecimentos agropecuários, São aproximadamente 4,4 milhões de estabelecimentos, sendo que a metade deles está na Região Nordeste, Brasil (2010).

A agricultura familiar tem dinâmica e características distintas em comparação à agricultura patronal. Nela, a gestão da propriedade é compartilhada pela família e a atividade produtiva agropecuária é a principal fonte geradora de renda, o agricultor familiar tem uma relação particular com a terra, seu local de trabalho e 'moradia'. A diversidade produtiva também é uma característica marcante desse setor. A Lei 11.326 de julho de 2006 define as diretrizes para formulação da Política Nacional da Agricultura Familiar e os critérios para identificação desse público, Brasil (2010).

A agricultura familiar constitui a base econômica de 90\% dos municípios brasileiros com até 20 mil habitantes; responde por $35 \%$ do produto interno bruto nacional; e absorve $40 \%$ da população economicamente ativa do país, é responsável por $87 \%$ da mandioca, $70 \%$ do feijão, $46 \%$ do milho, $38 \%$ do café, $34 \%$ do arroz e $21 \%$ do trigo no Brasil. Na pecuária, é responsável por $60 \%$ da produção de leite, além de 59\% do rebanho suíno, 50\% das aves e 30\% dos bovinos do país. A agricultura familiar possui, portanto, importância econômica vinculada ao abastecimento do mercado interno e ao controle da inflação dos alimentos consumidos pelos brasileiros, Brasil (2010).

A dinâmica da agricultura familiar com suas características tendem contribuir com a sustentabilidade local, isto posto pelas condições de administração da propriedade familiar e das condições de uso da terra, de modo que torna-se mais fácil ser incorporada pelos produtores familiares os conceitos da produção com viés sustentáveis territorial, isto que as necessidades da 
população presente e futura torna-se mais adequadas, quando a produção e suas características estiverem agregando identidades próprias ao desenvolvimento e as condições culturais locais, promovendo desenvolvimento territorial sustentável.

\subsection{Sustentabilidade e Desenvolvimento Territorial}

A definição de desenvolvimento sustentável é complexa, requerendo elementos muitas vezes que não condizem com os aspectos vigentes no processo, ainda assim, o conceito mais usual é dado no Relatório Brundtland, que define desenvolvimento sustentável como sendo "aquele que atende as necessidades do presente sem comprometer a possibilidade de as gerações futuras atenderem as suas próprias necessidades" Carvalho e Barcellos, (2010, p. 101).

Por sua dinamicidade, sustentabilidade é um termo complexo, que parte de um sistema de valores com foco diferenciado ao longo do tempo, mas que busca elementos que aproximem as condições de equilíbrio entre os conceitos. Assim sendo, é praticamente impossível obter um conceito único para o termo, no entanto, apesar da variação de entendimentos, existe certo consenso sobre o significado para o termo sustentabilidade em relação às necessidades de se reduzir a poluição ambiental, eliminar os desperdícios e diminuir o índice de pobreza, Baroni (1992).

Valorando os serviços ambientais, e entendendo o conceito de sustentabilidade como algo que aproxima os valores de identidade produtiva, cultural e social, a agricultura com base agroecológica e familiar sustentável possui papel especial na busca de equilíbrio entre as atividades agrícolas, a sustentabilidade e a produção de alimentos saudáveis. De acordo com Gliessman (2001) a agricultura sustentável é um processo que reconhece a natureza sistêmica da produção de alimentos, forragem e fibras, equilibrando com equidade, preocupações relacionadas com a saúde ambiental, justiça social e viabilidade econômica entre os diferentes setores da população, incluindo distintos povos em diferentes gerações.

A mudança sobre o espaço rural e seu papel na sustentabilidade ocorre quando os sistemas de valoração dos serviços ambientais rurais são postos em evidência, desse modo os conceitos de sustentabilidade e produção de alimentos com responsabilidade ambiental, social e viabilidade econômica se aproxima dando ao produtor rural responsabilidades nas quais ele se torna protagonista na gestão de sistema complexo, diversificado, integrado e interdependente.

Conciliar eficácia econômica, responsabilidade social e proteção do patrimônio natural, promovendo, ao mesmo tempo, serviços ecossistêmicos para a sociedade, torna-se uma questão estratégica e central para o produtor rural dar continuidade ao seu negócio, conforme enfatizam Ferreira et all. (2012). Desse modo, é essencial verificar os viés das políticas ambientais e a relação dessas com a atividade rural, sobretudo a atividade rural familiar, posto que, as políticas ambientais nos âmbitos dos entes federativos, apontam para a necessidade de estímulos ao produtor rural, isto posto, nas linhas diretrizes da Política da Secretaria de Desenvolvimento Territorial - SDT, quando vincula as discussões territoriais nos PTDRS - Plano Territorial de Desenvolvimento Rural Sustentável, ao tempo em que determina aos agricultores familiares a venda direta de seus produtos a alimentação escolar, através do PNAE - Programa Nacional de Alimentação Escolar, em atendimento a Lei 11.947/2009.

As políticas visam viabilizar a atividade em moldes sustentáveis, visto que é conhecida a dificuldade vivenciada pelos produtores rurais, principalmente pelos agricultores familiares, nos processos de regularização ambiental, ao mesmo tempo de adequar suas propriedades não somente para atendimento à legislação ambiental, mas também às demais dimensões da sustentabilidade, a econômica e social. Ferreira et all. (2012). Nesse sentido,ficaevidente a necessidade de promoção de processos educativos para aferição do desempenho econômico, social e ambiental na escala de estabelecimentos rurais, com o objetivo de auxiliar no processo de tomada de decisão.

No Território do Cariri Oriental Paraibano, o fórum de desenvolvimento territorial dedicou e dedica vultosa atenção as políticas de valorização da produção e comercialização dos produtos de origem agroecológica e ou orgânicas advindos da 
agricultura familiar com apoio ao produtor em atividades agrárias e agrícolas, sendo considerada atividade agrícolas ${ }^{3}$ as de apoio técnico produtivo "atividades da porteira para dentro" e agrárias ${ }^{4}$ atividades de comercialização e escoamento da produção "atividades da porteira para fora". De todas as ações voltadas ao setor, um que tem significado em número de agricultores atendidos tem sido a inserção de produtos oriundos da agricultura familiar na alimentação escolar.

De acordo com a Lei 11.947/2009, os Estados, o Distrito Federal e os municípios são obrigados a comprar produtos da agricultura familiar em no mínimo 30\% dos recursos repassados do Programa Nacional de Alimentação Escolar - PNAE, a política está em vigor há nove anos, o que é mister usar de parâmetros para averiguar a sustentabilidade e o desenvolvimento sustentável em base territorial, Brasil (2009). O sucesso dessa ação tem base explicativa no mercado formal e na garantia de recursos por dez meses a cada ano, período em que são repassados os recursos do PNAE as unidades escolares e essas compram por força de leia no mínimo trinta por cento desses recursos produtos da agricultura familiar.

A política valoriza a produção orgânica e/ou agroecológica na busca pelo fortalecimento de hábitos alimentares saudáveis, na tentativa de promover o desenvolvimento local de forma sustentável, abrindo, portanto, pressupostos para elaboração de indicadores que demonstre a eficácia da política no desenvolvimento local sustentável com base na política territorial do Ministério do Desenvolvimento Agrário - MDA da Secretaria de Desenvolvimento Territorial - SDT e do Ministério do Desenvolvimento Social - MDS, Brasil (2010).

Na prática, a Secretaria não se estruturou apenas como um exercício de orientação interna de suas ações, mas também, socializar o conjunto de órgãos colegiados e todos os agentes envolvidos na proposta, aqueles que podiam ser tomados como temas de referenciais para uma nova práxis no fomento ao desenvolvimento sustentável e as populações envolvidas, os agentes onde as discussões tornam-se possíveis de serem debatidas e avaliadas para posterior tomada de decisões, espaços nos quais as políticas em suas mais variadas situações poderiam serem postas em pauta. A SDT em suas linhas gerais busca orientar as práticas nos territórios, a partir de quatro grandes áreas de resultados: gestão social, redes sociais de cooperação, articulação de políticas e dinamização econômica de territórios rurais Brasil, (2010).

O Colegiado Territorial constitui-se em espaço privilegiado onde os quatro temas acima descritos e, suas consequentes ações, se inter-relacionam, se complementam, se articulam na formulação de propostas e estratégias para o desenvolvimento sustentável. A lógica é que as práticas da gestão social, da atuação em redes sociais, da articulação de política e da dinamização econômica encontrem no PTDRS (Plano Territorial de Desenvolvimento Rural Sustentável) o instrumento para materializar sua capacidade de pensar estratégica, de organizar suas demandas, de priorizar, propor, executar e monitorar projetos que potencializem resultados nessas áreas, Brasil (2010).

O Fórum é o instrumento que o território tem para mobilizar, articular, os atores sociais e consolidar a Estratégia de Desenvolvimento Territorial, assim como deliberar, planejar, direcionar e monitorar as ações de desenvolvimento, para conduzir o processo de gestão das ações do desenvolvimento do território. Ressalta-se que o desenvolvimento territorial em bases sustentáveis, apenas será possível mediante a interação de todos os atores envolvidos e em consonância sistêmica e equilibrada entre a humanidade e os fatores ecológicos, para que haja uma sustentabilidade dos fatores satisfatória as condições vigentes.

De acordo com essa perspectiva, a corporação deve desenvolver produtos e processos mais sustentáveis em resposta a estímulos externos, como a política do governo ou os movimentos sociais, e de acordo com os procedimentos estabelecidos pelos desafios técnicos da reestruturação ambiental, Dryzek, (1997), Hajer, (1995); Mol, (2000).

\footnotetext{
${ }^{3}$ As políticas agrícolas dizem respeito à produção Stictu Sensu (quantidade e preço dos vários produtos) em várias etapas desde a fazenda até a mesa do consumidor, Grazaiano da Silva Neto (1889, p. 128 apud Silva, 2015, p.63)

${ }^{4}$ As políticas agrárias dizem respeito às relações de produção, às formas de organização do trabalho, os níveis de renda e emprego dos trabalhadores rurais e a distribuição da propriedade da terra, Grazaiano da Silva Neto (1889, p. 128 apud Silva, 2015, p.63)
} 
Nesse sentido, e tendo como estruturas estratégicas de apoio os Núcleos Técnicos e Dirigentes, os Codeters (Colegiados de Desenvolvimento Territorial) a partir do diagnóstico da realidade local e do desenho da visão de futuro, organizam as prioridades territoriais em função de eixos, programas e projetos que traduzam a dinâmica dos diversos subespaços e atores articulados: unidade familiar, comunidades, municípios, espaços intermunicipais, espaços interestaduais e interterritoriais, conforme a necessidade para articulação do conjunto de políticas capazes de promover o desenvolvimento local territorial sustentável, em atendimento ao conjunto das políticas públicas.

Ante ao exposto, pode-se afirmar que relacionar indicadores de desenvolvimento com sustentabilidade e territorialidade, torna-se essencial para entender o desenvolvimento territorial sustentável nos territórios rurais.

Identificar indicadores que relacionem a agricultura familiar ao desenvolvimento sustentável é essencial para avaliação da eficácia das políticas públicas destinadas ao setor, sobretudo para averiguar a sustentabilidade da Agricultura Familiar $^{5}$, a partir do conceito de território.

De acordo com Mcqueen e Noak (1998) indicador é "uma medida que resume informações relevantes de um fenômeno particular ou um substituto dessa medida" de acordo com o conceito acima, é mister encontrar medidas que mensure os fenômenos de sustentabilidade entre os agricultores familiares e a política de desenvolvimento territorial com base na relação entre a produção familiar agrária, os conceitos vinculados a essa e a qualidade de vida inserida nesse processo.

Para OECD (1993) indicador é "um parâmetro, ou valor derivado de parâmetro que apontem e fornecem informações sobre o estado de um fenômeno, com uma extensão significativa", de sorte que se pode definir um indicador como sendo uma variável que está relacionada hipoteticamente com outra variável estudada, e, que a rigor não pode ou não está sendo diretamente observada, de modo que, um indicador de forma mais concreta pode ser entendido como uma variável.

Variáveis nesse sentido são representações operacionais de um atributo em um sistema, (qualidade, característica, propriedade), de modo que a variável não é o atributo, mas a representação, imagem ou abstração da variável, quão mais próxima for da realidade maior seu significado ou suas significações para a tomada de decisão; os indicadores de modo geral objetivam agregar e quantificar informações, de modo que sua significância fique mais aparente, os indicadores podem ser quantitativos e qualitativos, e, são utilizados nas tomadas de decisões.

Para Meadows (1998, p.12) "a utilização de indicadores é uma maneira intuitiva de monitorar complexos sistemas que a sociedade considera importantes e precisam controlar”. A sociedade mede o que ela valoriza e aprende a valorizar aquilo que ela mede. Nesse sentido, encontrar variáveis que mensurem a sustentabilidade do desenvolvimento territorial sustentável é um elemento significativo na tomada de decisão, especificamente no Território do Cariri Oriental Paraibano onde foram ao longo de mais de dez anos investidos recursos na formação e qualificação das famílias agricultoras, visando melhoria da qualidade de vida dessas, assim como agregação de valor a seus produtos com uso de tecnologias sociais no melhoramento dos produtos com ganho de vida de prateleira e a busca por mercados institucionais e diversos.

${ }^{5}$ Historicamente, a categoria do agricultor familiar data de tempos remotos da história da sociedade. O que se tem de recente nessa categoria são os rumos de sua análise e a importância que recentemente vem ganhando, especialmente no Brasil, Wanderley (2001, p.21).

A agricultura familiar é caracterizada por diferentes formas produtivas, ainda assim, para uma definição mais precisa, deve-se tomar por base características como: quantidade de mão de obra familiar ocupada na produção, condições de pose da terra, administração da unidade produtiva, número de trabalhadores contratados, entre outros fatores, Wanderley (2001, p.21).

$\mathrm{Na}$ legislação brasileira, a definição de propriedade familiar consta no inciso II do artigo $4^{\circ}$ do Estatuto da Terra, estabelecido pela Lei $\mathrm{n}^{\circ} 4.504$ de 30 de novembro de 1964, com a seguinte definição: propriedade familiar:o imóvel que, direta e pessoalmente explorado pelo agricultor e sua família, lhes absorvatoda a força de trabalho, garantindo-lhes a subsistência e o progresso social e econômico,com área máxima fixada para cada região e tipo de exploração, e eventualmente e na definição da área máxima, a lei no 8.629 , de 25 de fevereiro de 1993, estabelece como pequena propriedade os imóveis rurais com até 4 (quatro) módulos fiscais e como médias aquelas propriedade entre 4 e 15 módulos fiscais. Gonçalves e Souza (2005)

O programa de Fortalecimento da Agricultura Familiar PRONAF enquadra os produtores rurais como beneficiários de linhas de crédito rural quando atendem aos seguintes requisitos: sejam proprietários, posseiros, arrendatários, parceiros ou concessionários da Reforma Agrária, residam na propriedade ou em local próximo; detenham, sob qualquer forma, no máximo 4 (quatro) módulos fiscais de terra, quantificados conforme a legislação em vigor, ou no máximo 6 (seis) módulos quando tratar-se de pecuarista familiar com $80 \%$ da renda bruta anual familiar advinda da exploração agropecuária ou não agropecuária do estabelecimento e mantenham até 2 (dois) empregados permanentes, sendo admitida a ajuda eventual de terceiros. 
No território do Cariri Oriental ${ }^{6}$ Paraibano, a participação da agricultura familiar na constituição da renda e do desenvolvimento territorial assume fundamental importância, pois uma parcela significativa da população e da mão de obra ocupada tem suas atividades vinculadas à agricultura familiar, cujas ações estão estritamente vinculadas à natureza, está de acordo com a Agenda 21 (1995, cap. 32) “a agricultura ocupa um terço da superfície da terra, e constitui a atividade central de grande parte da população mundial. Atividades rurais ocorrem em contato estrito com a natureza, a que agrega valor com a produção de recursos renováveis, ao mesmo tempo em que se tornam vulneráveis à exploração excessiva ao manejo inadequado".

Sendo assim, as famílias rurais como apresentado acima, além de serem importantes na constituição da própria ocupação, estão diretamente ligados a atividades vinculadas a natureza, o que se torna essencial a compreensão da eficiência das políticas públicas destinadas às atividades rurais, especialmente as atividades da agricultura familiar, no Cariri Oriental Paraibano, a análise da eficácia dessas políticas torna-se ímpar, uma vez que é a agricultura familiar responsável por significativa ocupação da mão de obra no setor rural, além de ser responsável por parcela significativa do PIB - Produto Interno Bruto do território.

\section{Metodologia}

A pesquisa do tipo exploratória descritiva qualitativa com caráter indutivo Pereira (2018), defende que a indução parte do si só do particular, deixando a generalização como um produto posterior, uma vez que os atos e os fenômenos devem ser entendidos em principio e posterior compara-se a necessidade de conhecer o fenômeno como um todo Gil (2010), foi realizada nos municípios do Território do Cariri Oriental Paraibano, que é composto por Alcantil, Barra de Santana, Barra de São Miguel, Boa Vista, Boqueirão, Cabaceiras, Caraúbas, Caturité, Gurjão, Riacho de Santo Antônio, Santo André, São Domingos do Cariri, São João do Cariri e Soledade.

Para coleta de dados foram solicitados os relatórios das secretarias municipais de desenvolvimento econômico dos municípios que compõem o território, os relatórios e atas das reuniões do Fórum de Desenvolvimento Territorial do Cariri Oriental, e o PTDRS (2010) - Plano Territorial de Desenvolvimento Rural Sustentável, assim como os documentos oficiais do MDA - Ministério do Desenvolvimento Agrário, e principalmente dado do IBGE - Instituto Brasileiro de Geografia e Estatística. Os dados obtidos foram analisados em planilha do Excel dos resultados para PIB, PIB Per Capita e IDH do território, assim como a relação área produzida e população residente nos centros urbanos e rurais. Os documentos analisados datam dos últimos dez anos e a coletada de dados deu-se no período compreendido entre janeiro 2020 a maio 2021.

As principais variáveis para compreensão do processo de desenvolvimento e os parâmetros para esses foram o PIB, o PIB Per Capita e IDH do ponto de vista macro do desenvolvimento para o território; do ponto de vista micro, os principais parâmetros foram à densidade demográfica nos municípios, população economicamente ativa, tipo de atividade nas propriedades e a administração do imóvel rural familiar, para averiguar se a agricultura familiar proporciona à população residente as condições mínimas de sobrevivência e se é capaz de promover o desenvolvimento regional sustentável.

\footnotetext{
${ }^{6} \mathrm{~A}$ região do Cariri Oriental perfaz um total $44.457 .00 \mathrm{~km}^{2}$, representando 7,87\% do Estado; possui cerca 83.670 habitantes, dos quais, 42.922 habitantes nas áreas urbanas (51\%) e 40.748 nas áreas rurais (49\%). Possui 6.636 estabelecimentos caracterizados como da agricultura familiar e 13.723 habitantes em extrema pobreza (IBGE, 2010). Quanto ao Índice de Desenvolvimento Humano (IDH), possui média de 0,586. É composto por quatorze municípios (Alcantil, Barra de Santana, Barra de São Miguel, Boqueirão, Cabaceiras, Caraúbas, Caturité, Gurjão, Riacho de Santo Antônio, Santo André, São Domingos do Cariri, São João do Cariri, Soledade e Boa vista)
} 


\section{Resultados e Discussões}

O Território do Cariri Oriental - PB é composto por 14 municípios, a saber Alcantil, Barra de Santana, Barra de São Miguel, Boa Vista, Boqueirão, Cabaceiras, Caraúbas, Caturité, Gurjão, Riacho de Santo Antônio, Santo André, São Domingos do Cariri, São João do Cariri e Soledade, PTDRS (2010), ver Figura 1.

Figura 1 - Municípios que compõem o Território do Cariri Oriental da Paraíba.

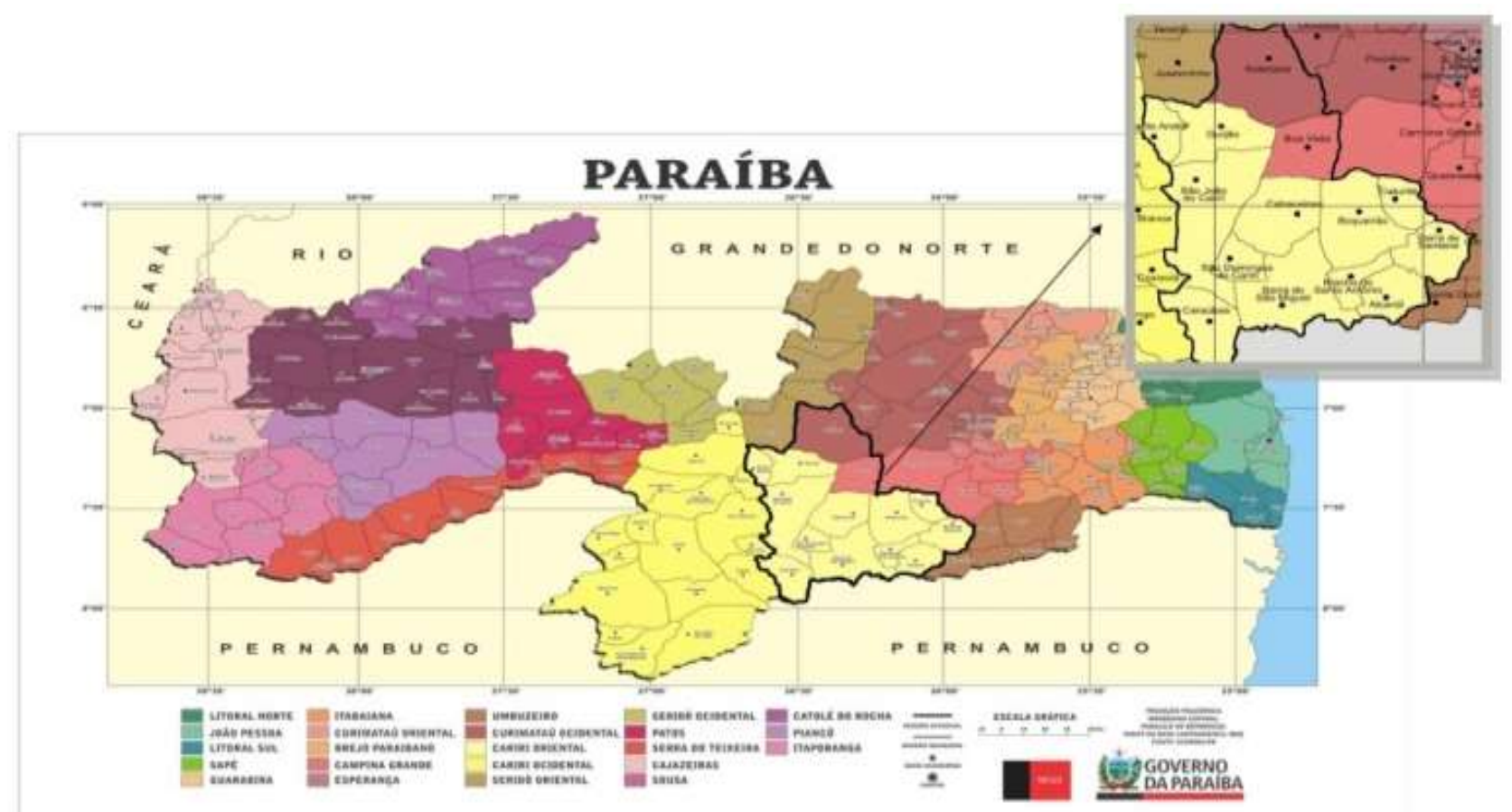

Fonte: http://mapasblog.blogspot.com.br/2011/12/mapas-da-paraiba.html (acesso 12/2021).

O território encontra-se na porção centro-sul do Estado, entre as coordenadas de $7^{\circ}$ e $8^{\circ} 30^{`}$ latitude sul e $36^{\circ}$ e $37^{\circ} 30^{\prime}$ de longitude oeste, com altitude para níveis de 400 a 600 metros, em direção ao entalhamento do rio Paraíba, que forma uma rasa depressão intermontana, situada em cotas altimétricas de 300 metros, em vale encaixado e estreito. No sentido leste/oeste esse planalto se estende, desde a retaguarda da frente oriental escarpada até o limite das suas encostas ocidentais, com o Pediplano Sertanejo. Interrompe-se ao norte, no vale tectônico do Curimataú, e ao sul, prolonga-se até a fronteira com Pernambuco, onde encontra os alinhamentos de cristas que se elevam a mais de $800 \mathrm{~m}$, como as serras das Umburanas, Serra de Acaí, Serra do Jabitacá, PTDRS (2010).

Por sua localização, no espaço central do Estado situado mais ao sul, na divisa com Pernambuco, uma área significativa do território sofre muita influência de cidades pernambucanas, sobretudo daquelas que estão na zona de influência de Santa Cruz, situadas na porção ao norte do Território sofre influência econômica do município de Campina Grande, PTDRS (2010).

A estratégia de desenvolvimento territorial trabalha o desenvolvimento considerando o território como uma unidade estratégica para planejamento e execução de políticas públicas, sendo o território um espaço geográfico detentor de relações de identidade cultural, econômica, ambiental, política e social.

As relações travadas entre os diversos agentes constituintes dos territórios são determinantes na constituição e fortalecimento dos mesmos, de sorte que a compreensão de suas atividades econômicas, modo de vida, suas relações com o meio ambiente, determinam as condições de identidade. Assim, as condições de produção e as relações dessa com o meio não 
determinam apenas a elevação do PIB - Produto Interno Bruto e o poder de compra dos agentes, mas a qualidade dessa evolução e/ou os entraves no conjunto de suas relações.

No Cariri Oriental Paraibano, os agentes envolvidos no processo produtivo identitário dessa realidade, têm suas bases produtivas arraigadas na agricultura familiar, e os que por ventura não tem a renda principal oriunda das atividades agrícolas, de uma forma ou de outra ainda mantém relações com o meio rural, ou por meio de um parente ou por deter glebas de terras cultiváveis onde realizam atividades constantemente, seja por meio de mão de obra contratada, seja por meio de mão de obra da própria familiar, grosso modo são aposentados, e/ou funcionários públicos, representa a única categoria social que no Cariri Oriental, não tem sua principal fonte de renda advinda da atividade rural.

Os municípios do Cariri Oriental Paraibano têm suas atividades diretamente vinculadas ao setor rural, mesmo que em alguns municípios a população urbana ultrapasse a rural, a atividade principal ainda é à agricultura, morram na cidade, mas trabalham nos sitio e fazendas. De acordo com o ultimo senso, a população do Território do Cariri Oriental, está distribuído conforme demonstrado $n$ Tabela 1 abaixo.

Tabela 1 - População residente (rural e urbana) e Produto Interno Bruto (total e per capita), por município do Cariri Oriental paraibano (2010)

\begin{tabular}{|c|c|c|c|c|c|c|c|}
\hline \multirow{2}{*}{$\begin{array}{c}\text { MunicípiosCariri Oriental - } \\
\text { PB }\end{array}$} & \multicolumn{3}{|c|}{$\begin{array}{c}\begin{array}{c}\text { Populaçãoresidente } \\
\text { (Pessoas) }\end{array} \\
\end{array}$} & \multicolumn{2}{|c|}{$\begin{array}{c}\text { Populaçãoresidente } \\
\text { (Percentual) }\end{array}$} & \multirow{2}{*}{$\begin{array}{l}\text { PIB } \\
(\mathbf{R} \$) \\
2010\end{array}$} & \multirow{2}{*}{$\begin{array}{c}\text { PIB per } \\
\text { Capita } \\
(\mathbf{R} \$) 2010\end{array}$} \\
\hline & Total & Urbana & Rural & Urbana & Rural & & \\
\hline Alcantil & 5.239 & 2.064 & 3.175 & 39,4 & 60,6 & 25.173 & 4.805 \\
\hline Barra de Santana & 8.206 & 731 & 7.475 & 8,91 & 91,09 & 35.683 & 4.348 \\
\hline Barra de São Miguel & 5.611 & 2.364 & 3.247 & 42,13 & 57,87 & 26.737 & 4.765 \\
\hline Boa Vista & 6.227 & 3.208 & 3.019 & 51,52 & 48,48 & 89.904 & 14.438 \\
\hline Boqueirão & 16.888 & 12.006 & 4.882 & 71,09 & 28,91 & 105.103 & 6.224 \\
\hline Cabaceiras & 5.035 & 2.217 & 2.818 & 44,03 & 55,97 & 25.094 & 4.984 \\
\hline Caraúbas & 3.899 & 1.517 & 2.382 & 38,91 & 61,09 & 20.110 & 5.158 \\
\hline Caturité & 4.543 & 1.024 & 3.519 & 22,54 & 77,46 & 35.923 & 7.907 \\
\hline Gurjão & 3.159 & 2.128 & 1.031 & 67,36 & 32,64 & 17.070 & 5.404 \\
\hline Riacho de Santo Antônio & 1.722 & 1.186 & 536 & 68,87 & 31,13 & 10.809 & 6.277 \\
\hline Santo André & 2.638 & 865 & 1.773 & 32,79 & 67,21 & 13.547 & 5.135 \\
\hline São Domingos do Cariri & 2.420 & 1.034 & 1.386 & 42,73 & 57,27 & 12.317 & 5.090 \\
\hline São João do Cariri & 4.344 & 2.347 & 1.997 & 54,03 & 45,97 & 22.844 & 5.259 \\
\hline Soledade & 13.739 & 10.231 & 3.508 & 74,47 & 25,53 & 75.367 & 5.486 \\
\hline
\end{tabular}

Fonte: IBGE, (2010), adaptado pelos autores (2022).

Dos 14 (quatorzes) municípios que compõem o território, apenas Boa Vista, Boqueirão, Gurjão, Riacho de Santo Antônio, São João do Cariri e Soledade apresentam população urbana superior à população rural. Boqueirão com 71,09\% da população residente na zona urbana e $28,91 \%$ na zona rural e Soledade com $74,47 \%$ da população na zona urna e 25,53\% na zona rural são os dois municípios com maior expressividade de pessoas residindo nos espaços urbanos. Riacho de Santo Antônio com 68,87\% dos habitantes urbanos e 31,13\% rurais, seguido por Gurjão com 67,36\% de pessoas na zona urbana e 32,64 \% na zona rural, São João do Cariri com 54,03\% no setor urbano e 45,97\% no setor rural e por último, Boa Vista com $51,52 \%$ de pessoas no espaço urbano e $48,48 \%$ nos espaços rurais.

As possíveis explicações para essa realidade pode ser dadas por motivos diversos e significativamente diferentes, no caso de Boqueirão as explicações pautam-se na proximidade com Campina Grande, uma vez que muitas das pessoas residentes 
em Boqueirão, mas realizam suas atividades laborais em Campina Grande, outro fator é a população jovem em busca de qualificação se utilizam dessa proximidade para realizar seus estudos em Campina Grande, outro fator pauta-se na área banhada pelo Açude Público Epitácio Pessoa, ser utilizado para produção agrícola, que mesmo sendo de origem e caracteristicamente de cunho familiar, organiza-se e atende a condições muito próximas da agricultura patronal, fator que leva as pessoas a residirem no espaço urbano e voltam todos os dias para os espaços rurais para realizarem suas atividades laborais, com propensão marginal crescente da renda advinda da agricultura irrigada, trazem as famílias para o espaço urbano na busca por qualidade de vida, entendendo assim, os serviços urbanos como sendo detentor potencial de qualidade de vida.

O Município de Soledade é beneficiado pela BR-230, o que fortalece o comércio e muitos dos habitantes dos espaços rurais migram para o espaço urbano para aproveitar desse potencial, além da proximidade com Campina Grande, proporcionando aos jovens irem até Campina em busca de qualificação, assim como em busca de emprego, especialmente no comercio e na indústria.

Os demais municípios tendem explicar a saída do setor rural para o urbano em função da violência que ao longo dos últimos anos tem crescido no setor rural, exceto Boa Vista que também é beneficiada pela BR-412, o que fortalece o comercio e a extração de mineração, especialmente Betonita e Balxita, realidade que em muito ocupa a mão de obra local. De sorte que Boa Vista, tem na extração mineral fonte significativa de renda e de ocupação da PEA - População Economicamente Ativa. Ainda assim, o setor rural e suas atividades estão em significativa expansão, ver tabela 2. Ainda assim, para Boa Vista, há forte tendência a uma mudança da realidade, isto é, de sua principal fonte de renda migrar das atividades agropastoris familiar para a extração mineral exclusivamente patronal; cada realidade, para cada município influência diretamente o desenvolvimento e a relação PIB e PIB per capita dos municípios.

A relação PIB e PIB Per capita, retrata grosso modo, o quão distribuído está a produção de riqueza na região, Estado ou Município, para o Território do Cariri Oriental Paraibano, a relação PIB e PIB Per Capita apresenta variáveis interessantes, pois dentre todos os municípios que compõem o território, Boqueirão apresenta o maior PIB com um montante na ordem de 105.103 (cento e cinco milhões e cento e três mil) e Riacho de Santo Antônio o menor PIB com 10.809 (dez milhões cento e três mil) os demais municípios tem PIB oscilando entre esses dois municípios.

Em se tratando de PIB, Per Capita encontra-se às particularidades inerentes as diferentes realidades, nessa categoria Boa Vista que apresenta PIB de 89.904 (Oitenta e Nove Milhes e Noventa e Quatro Mil) apresenta melhor distribuição de Renda com um PIB Per Capita de 14.138 (Quatorze Mil Cento e Trinta e Oito), Riacho de Santo Antôniocom pior PIB entre os demais, apresenta melhor PIB Per Capita, em termos proporcionais com 6.277 (Seis Mil Duzentos e Setenta e Sete) e, Boqueirão com o melhor PIB em se tratando de PIB Per Capita aparece em terceiro lugar com 6.224 (Seis Mil Duzentos e Vinte e Quatro). Os demais municípios oscilam com PIB Per Capita entre 4 (Quatro Mil) e 5 (Cinco Mil), mantendo um certo equilíbrio entre a distribuição da riqueza.

A relação PIB e PIB Per Capita, demonstra o quão diferente são as realidades no Território do Cariri Oriental Paraibano, desde a distribuição da renda quando municípios com PIB não muito elevados consegue distribuir melhor a renda até a concentração da renda, quando municípios com rendas relativamente altas distribuem mal, o que reflete no poder de compra e consequentemente na qualidade de vida das pessoas, observar tabela 1, ainda assim, quando se observa o Índice de Desenvolvimento Humano para o território, observa-se que este tem características de médio desenvolvimento humano que são aqueles IDHs que mantém uma relação entre 0,5 e 0,8 , fatores que devem serem observados pelos prismas das entradas de recursos no território, uma vez que recursos advindos de transferências como programas do Governo Federal devem serem analisados sobre pontos de vistas diferentes, dados os possíveis gastos desses recursos e a identidade do mesmo. Ver tabela 2. 
Tabela 2 - Caracterização do Território Cariri Oriental.

\begin{tabular}{l|c|c|c}
\hline \multicolumn{1}{c|}{ Municípios } & Área $\left.\mathbf{( k m}^{\mathbf{2}}\right)$ & $\begin{array}{c}\text { Densidade } \\
\text { demográfica }(\mathbf{h a b} / \\
\mathbf{k m} \mathbf{2}\end{array}$ & IDHM 2010 \\
\hline Alcantil & 305.394 & 17,15 & 0,578 \\
\hline Barra de Santana & 376.912 & 21,77 & 0,567 \\
\hline Barra de São Miguel & 595.211 & 09,43 & 0,572 \\
\hline Boa Vista & 476.541 & 13,07 & 0,649 \\
\hline Boqueirão & 371.984 & 45,40 & 0,607 \\
\hline Cabaceiras & 452.922 & 11,12 & 0,611 \\
\hline Caraúbas & 497.204 & 07,84 & 0,585 \\
\hline Caturité & 118.081 & 38,47 & 0,623 \\
\hline Gurjão & 3.311 & 09,20 & 0,625 \\
\hline Riacho de S. Antônio & 91.324 & 18,86 & 0,594 \\
\hline Santo André & 225.169 & 11,72 & 0,600 \\
\hline São Domingos do Cariri & 218.801 & 11,06 & 0,589 \\
\hline São João do Cariri & 653.602 & 06,65 & 0,622 \\
\hline Soledade & 560.042 & 24,53 & 0,616 \\
\hline
\end{tabular}

Fonte: IBGE Cidades (2010). Adptado pelos autores (2022).

De acordo com a Tabela 3, a realçao entre o Índice de Desenvovlimento Humano em relação ao PIB e ao PIB Per Capita, não retrata uma equidade na distribuição de renda, pois os municipios com melhor PIB e PIB Per Capita possuem IDH inferior a Barra de Santa com IDH de 0,667 que não esta entre os melhores PIBs e PIBs Per Capita da Região, em realção ao IDH seguido por Barra de Santana encontra-se Boa Vista com IDH de 0,649 e Boquierão com IDH de 0.607. Ao analisar a Tabela 1 e a Tabela 3, verifica-se que a relação PIB, PIB Per Capita e IDH não caminham na mesma direção, tampouco tem sentidos claramente opostos, o que percebe-se são pequenas oscilações entre a produção da riqueza a distribuição dessa e a qualidade de vida das pessoas, ver Gráfico 1 .

Gráfico 1 - Relação PIB, PIB Per Capita e IDH no Território do Cariri Oriental.



Fonte: IBGE Cidades, (2010) adaptado pelos autores (2022).

De acordo com o gráfico apresenta discrepância entre a produção da riqueza, a distribuição da renda é a qualidade de vida, uma vez que, mesmo apresentando PIB elevado, o PIB Per Capita não acompanha uma relação equitativa entre as partes ao mesmo tempo em que a qualidade de vida não acompanha os mesmos níveis de crescimento, posto que salvas exceções a exemplo de Riacho de Santo Antônio, Santo André e Gurjão, onde PIB e PIB Per Capita são razoavelmente equitativos, os demais municípios apresentam PIB maior que PIB Per Capita, sendo a maior diferença nos municípios de Barra de São Miguel, Boa Vista, Boqueirão, Cabaceiras, São João do Cariri e Soledade.

A elevada diferença entre os índices econômicos PIB e PIB Per Capita, revela a tendência desses municípios mesmo sendo rurais a atenderem as exigências e características produtivas vinculadas ao mercado, fator que para a análise que se propõem esse trabalho meio que descaracteriza a propriedade rural familiar, nos requisitos de produção de subsistência e a 
coloca nas condições características de familiar mercadológica, isto é, sai, da categoria campesina em sua gênesis e sobrepõem-se as condições organizativas determinadas pelo mercado, essa condição sui gênesis vincula a propriedade familiar da região resguardadas as condições capitalistas de produção, o que grosso modo atende aos viés das políticas desenvolvidas para o setor, desvincula o agricultor familiar da situação de produtor de alimentos a ser consumido no seio da própria unidade produtiva.

As condições descritas acima e observadas na análise dos dados deixam claro que a unidade familiar no Cariri Oriental Paraibano passa por um processo de transição, deixando de ser caracteristicamente produtora de alimentos destinados ao consumo da família e comercialização do excedente, condição essa que está na gênesis do processo constitutivo da atividade, para uma realidade mais mercadológica, voltada para os ganhos comparativos, nos quais o agricultor produz vislumbrando a comercialização da produção e esta, mesmo sendo familiar pelas condições de produção e posse da terra atende claramente as condições e exigências do mercado.

Desse modo, a unidade produtiva familiar no Cariri Oriental Paraibano, tende a tornar-se completamente mercantil, e, nesse sentido, a análise demonstra uma tendência a perca de identidade local, pois o produto assume condições diversificadas, e essas condições passam a gerir o próprio planejamento produtivo, o que a depender da análise ou do observador, todas as condições tendem para a positividade dada as relações mercadológicas e os ganhos de escalas, além do visível crescimento da riqueza local, especialmente para os municípios com maior urbanização, no entanto por outro lado, e a depender da observação realizada, a região ganha em relações produtivas e eficiência mercadológica, mas perde em identidade, em qualidade de vida, já que os únicos índices a serem considerados na análise foram os econômicos, pois os sociais e ambientais ainda são insipientes na análise.

As condições postas, e, apesar das características tenderem para a produção de mercado, a população economicamente ativa do Cariri Oriental Paraibano vincula-se em sua maioria nas atividades agrícolas de cunho familiar, essas características podem ser observadas nos dados da Tabela 3.

Tabela 3 - População Economicamente Ativa Ocupada no Cariri oriental por Ramo de Atividade.

\begin{tabular}{l|c|c|c|c}
\multicolumn{1}{c|}{ Município } & $\begin{array}{c}\text { Atividades } \\
\text { Agropecuárias }\end{array}$ & Indústria & $\begin{array}{c}\text { Administração } \\
\text { Pública }\end{array}$ & Comércio \\
\hline Alcantil & 1.073 & 377 & 101 & 152 \\
\hline Barra de Santana & 2.123 & 62 & 127 & 142 \\
\hline Barra de São Miguel & 1.306 & 219 & 162 & 199 \\
\hline Boa Vista & 1.167 & 189 & 154 & 899 \\
\hline Boqueirão & 5.402 & 1.507 & 352 & 223 \\
\hline Cabaceiras & 1.079 & 284 & 233 & 118 \\
\hline Caraúbas & 1.604 & 153 & 151 & 122 \\
\hline Caturité & 1.454 & 228 & 34 & 140 \\
\hline Gurjão & 1.729 & 26 & 167 & 63 \\
\hline Riacho de Santo Antônio & 449 & 97 & 151 & 87 \\
\hline Santo André & 1.363 & 9 & 106 & 74 \\
\hline São Domingos do Cariri & 734 & 279 & 91 & 197 \\
\hline São João do Cariri & 1.491 & 46 & 252 & 947 \\
\hline Soledade & 3.360 & 434 & 404 & $\mathbf{3 . 6 0 9}$ \\
\hline Total & $\mathbf{2 4 . 3 3 4}$ & $\mathbf{3 . 9 1 0}$ & $\mathbf{2 . 4 8 5}$ & \\
\hline
\end{tabular}

Fonte: IBGE (2010) adaptado pelos autores (2022): ocupação: agricultura, pecuária, pesca, aquicultura e à indústria extrativa e de transformação.

De acordo com os dados da Tabela 3, a maioria da população economicamente ativa-PEA do Cariri Oriental Paraibano, se encontra nas atividades agropecuárias, com um total de 24.334 (vinte e quatro mil trezentos e trinta e quatro) pessoas, seguido pela indústria com 3.910 (três mil novecentos e dez) pessoas, comércio com 3.609 (três mil seiscentos e nove) pessoas e administração pública com 2.485 (dois mil quatrocentos e oitenta e cinco) pessoas. 
O setor rural apresenta maior expressividade em todo o território, com todos os municípios com significativo número de pessoas ocupadas nas atividades agrícolas. Em todos os casos, somando as pessoas ocupadas na indústria na administração pública e nos serviços o resultado é inferior ao número de pessoas ocupadas nas atividades agropecuárias.

De sorte que, mesmo tendo municípios com número de habitantes urbanos superior aos habitantes rurais, a ocupação da população ocorre nos espaços rurais, isso demonstra que a ocupação dos espaços urbanos nesses municípios ocorre por motivos diversos, dos quais se pode elencar a insegurança no setor rural, a diminuição do número de pessoas por famílias e as oportunidades de escolarização existente nos espaços urbanos, no entanto, a principal fonte de renda dos municípios ainda é o setor rural, mesmo não pagando os melhores salários, são as atividades rurais quem determinam o PIB, e o desenvolvimento dos municípios do Território do Cariri Oriental Paraibano, MDA (2010).

\section{Considerações Finais}

As discussões para com as alterações de desenvolvimento aliadas a sustentabilidade ambiental, tem crescido nas pautas de movimentos sociais, assim como em organizações internacionais e centros universitários, isso posto pela crescente atenção dada ao meio ambiente a partir das discussões nos fóruns ambientais internacionais, em especial a partir da eco-92; assim sendo, passa a se compreender as atividades de cunho agroecológicas como forte potencial do desenvolvimento sustentável e esse como promovedor do desenvolvimento regional. Para a região do Cariri Oriental paraibano os fatores limitantes para esse desenvolvimento perpassam pelo tamanho da propriedade, limitando aos produtores baixo valor bruto de produção e, empobrecimento da população.

O tamanho limitado dos estabelecimentos familiares, no Cariri oriental compromete a viabilidade financeira, uma vez que a escala de produção se torna um problema estrutural para tipo de agricultura agricultor. Estudos indicam que, em média, o valor bruto de produção mensal por propriedade familiar é de 0,46 salários mínimo, IBGE (2010), o que coloca grande parte dos produtores em situação de extrema pobreza. No Nordeste, por exemplo, $72 \%$ dos produtores não geram lucro suficiente no estabelecimento para elevar a mão de obra familiar acima da linha de pobreza. Inevitavelmente, essa realidade tem reflexo danoso na sustentabilidade dos estabelecimentos rurais familiares, IBGE (2010).

A inovação pode criar condições para a manutenção da viabilidade econômica das propriedades familiares e sua capacidade de se reproduzir como unidade social familiar, além de poder contribuir para a modernização do setor. Essa modernização passa pela capacitação, pelo uso de insumos adequados, de máquinas e equipamentos apropriados ao segmento e às condições dos agricultores familiares, como forma de permitir sustentabilidade e ganhos significativos de produtividade.

É necessário desmistificar a crença de que o agricultor familiar busca, basicamente, a subsistência e, além disso, quebrar as barreiras que impactam sua transformação em empreendedor rural. Agricultores devem estar atentos ao modo como tomam suas decisões e devem identificar estratégias para organizar seu processo produtivo, com o intuito de agregar valor a seus produtos e maximizar a inserção nos mercados. Sob essa ótica, torna-se também importante criar estratégias que viabilizem diferentes formas de associação dos pequenos produtores, a fim de melhorar sua capacidade de negociar compras de insumos, bem como encontrar mercados mais estáveis para seus produtos.

O agricultor encontra, cada vez mais, um consumidor mais exigente sobre a decisão de compra. Agora, em sua avaliação, esse consumidor considera um conjunto de fatores como preço e qualidade, origem, procedência, sustentabilidade, relação com o meio ambiente, com os colaboradores e comunidades participantes do processo. Assim, diferentes oportunidades se apresentam para o pequeno produtor. Uma delas é a exploração da biodiversidade em associação com indústrias. A biodiversidade é matéria-prima essencial para a bioindústria e, essas condições vinculam diretamente a produção local no Território do Cariri Oriental Paraibano, nesse sentido, pode ser citado o associação de agricultores familiares produtores de leite com a indústria de beneficiamento desse produto com os mercados institucionais, o exemplo mais significativo é a relação 
entre produtores de leite de cabra com a COAPECAL - Cooperativa Agropecuária do Cariri e o Governo do Estado com o Programa do Leite. PTDRS (2010).

Outras possibilidades de acesso dos agricultores familiares a diferentes mercados abrangem nichos alternativos de comercialização, que demandam produtos com maior valor agregado. Dentre elas estão os produtos tradicionais, que atendem crescente demanda por produtos artesanais (slowfood) ou pelos aspectos éticos (fair trade), étnicos ou mesmo relacionados apenas com a sustentabilidade. A ampliação da presença da agricultura familiar fortalece movimentos vinculados à qualificação de produtos com indicação geográfica — aqueles com denominação de origem ou indicação de procedência —, contribuindo para o desenvolvimento do turismo rural relacionado à gastronomia. Muito comum na União Europeia, produtos com denominação de origem são alternativa para dinamizar atividades agrícolas tradicionais, principalmente as desenvolvidas em minifúndios ou regiões rurais fragilizadas economicamente. Essa pratica no Cariri Oriental, já vem se fortalecendo com os produtos de caprinos a exemplos da caprinocultura atividade que se fortalece em todo o território.

$\mathrm{O}$ trabalho ora proposto buscou abranger aspectos na produção que demonstrasse a partir dos indicadores de sustentabilidade o quão a produção familiar no Território é sustentável, deixando de abranger os possíveis impactos que a educação pode proporcionar na melhoria da produção familiar a partir da observação e incorporação a esta dos serviços ambientais sistêmicos, de sorte que este pode ser um aspecto a ser considerada em pesquisas futuras que tencione dar continuidade à pesquisa, na busca pela compreensão do quão importante é a educação na promoção da sustentabilidade considerada a produção familiar em parceria aos serviços ambientais sistêmicos.

\section{Bibliografia}

Amaral Filho, J. (1996). Desenvolvimento regional endógeno em um ambiente federalista. In: Planejamento e políticas públicas. Brasília, IPEA (14).

Antonio A. M. J., \& Zacarias X. de B (2020). Utilização Racional de Água em Cervejaria Brasileira. Energia na Agricultura 35(2), 287-294,

Baroni, M. (1992). Ambiguidade e deficiência do conceito de Desenvolvimento Sustentável. Revista de administração de Empresas, 32(2), 14-24.

Brasil, Câmara dos Deputados (2018). Conferência das Nações Unidas sobre o Meio Ambiente e Desenvolvimento (1992.: Rio de Janeiro). Biblioteca Digital da Câmara dos Deputados, centro de documentação e informação, coordenação de biblioteca.

Brasil, Ministério do Desenvolvimento Agrário MDA - (2010), Secretaria de Desenvolvimento Territorial - SDT: documento referencias para a dinamização econômica nos territórios rurais.

Carvalho, P. G. M. de. \& Barcellos, F. C. (2010). Economia do meio ambiente: teoria e pratica / Peter H. May (2a ed.), Elsevier.

Dryzek, J. (1997), The Politicsofthe Earth, Oxford University Press.

Ferreira, et al. (2012). Indicadores de sustentabilidade em agroecossistemas. Informe agropecuário, 33(271), 12-25.

Franzluebbers, A.J. (2021). Soil Organic Carbon Sequestration Calculated from depth distribution. Soil Sci.Sac. Am J. (85), 158-171.

Gil, A. C. (2008). Métodos e técnicas de pesquisa social. (6a ed.), Ediitora Atlas SA.

Gliessman, S. R. (2001). Agroecologia: processos ecológicos em agricultura sustentável, (6a ed.), Ed. Universidade/UFRGS.

Gonçalves, J. S., \& Souza, S. A. M. (2018) Agricultura familiar: limites do conceito e evolução do crédito. Artigos: políticas públicas. Instituto de Economia Agrícola.

Hajer, M. (1995), The Politics of Environmental Discourse, Oxford: Clarendon Press.

May, P. H. (2010) Economia do meio ambiente. Teoria e prática / Peter H. May (6a ed.), Elsevier.

Mcqueen, D., \& Noak, H. (1998). Healt promotion indicators: current status, inssues and problems. Health Promotion.

Meadows, D. (1998). Indicators and informations systems for sustainabled evelopment. Hartland Four Corners: The Sustainability Institute.

Mol, A. \& Sonnenfeld, D. (2000), EcologicalModernisationAtoundthe World: Na Introdution, Environmental Politics.

Leopoldo, N. C. M., et al. (2020). Vulnerabilidade ambiental do Parque Nacional das Nascentes do Rio Parnaíba - PNNRP. Gaia Scientia.

OECD (1993) - Organization For Economic Cooperation and Development - Organization for Economic Cooperation and Development: Core set of indicators for environmental performance reviews, a synthesis reportby the grupo on thestate of theenviroment. Paris. 
Research, Society and Development, v. 11, n. 2, e40111225827, 2022

(CC BY 4.0) | ISSN 2525-3409 | DOI: http://dx.doi.org/10.33448/rsd-v11i2.25827

Pereira, A. S., Shitsuka, D. M., Parreira, F. J., \&Shitsuka, R. (2018). Metodologia da pesquisa científica.

Rafael Felipe R. R. M. Cavalcanti, J. E. da S. \& Isabel L. F. (2021). "Water Cost Of Beer Production: A Comparative Economic Analysis in Brazil”, international journal of development research, 11, (02), 44856-44860.

Rafael Felipe R. R. M. Cavalcanti, J. E. da S. \& Isabel L. F. (2021). "Custos Da Água Na Produção De Cerveja: Uma Análise Econômica Comparativa” ,Resarch, Society and Development .10.33448/rsd-v.10i2.12765.

Resumo Executivo, Plano Territorial de Desenvolvimento Rural - PTDRS (2010). Território do Cariri Oriental-PB.

Silva, E. M. S. et al. (2016) Sustentabilidade e responsabilidade social ambiental: o uso indiscriminado de água. Revista Maiêtica, Indoial, 4(1), 57-66.

Silva, J. E. da. (2015). Análise da Viabilidade econômica da agricultura familiar dos arrendatários do DNOCS no Açude de Boqueirão-PB, Novas Edições Acadêmicas.

Tsur, Y. (2005) Economic aspects of irrigation water pricing. Canadian Resources Jiural, 30(1), 31-466,USGS.gov./Science for a changing world. Consultadoem 27/08/2021.

Wanderley, N. (2001). Raízes históricas do campesinato brasileiro. In: Tedesco (Org.) Agricultura familiar: realidades e perspectivas. Passo Fundo- RS: UPF, $405 \mathrm{p}$.

Zhiwei, W., et al. (2020). Streamflow Reconstruction and Variation Characteristic Analysis of the Ganjiang River in China for the Past 515 Years. NDPI. Sustenability. 